\title{
Concurrent comparison of epidemiology, clinical presentation and outcome between adult patients suffering from the pandemic influenza A (H1N1) 2009 virus and the seasonal influenza $A$ virus infection
}

\author{
Kelvin K W To, Samson S Y Wong, Iris W S Li, Ivan F N Hung, Herman Tse, \\ Patrick C Y Woo, Kwok-Hung Chan, Kwok-Yung Yuen
}

Infectious Disease Division, Queen Mary Hospital, State Key Laboratory of Emerging Infectious Diseases, Carol Yu Centre for Infection, The University of Hong Kong, Hong Kong Special Administrative Region, China

\section{Correspondence to}

Professor Kwok-Yung Yuen, Carol Yu Centre for Infection and Division of Infectious Diseases, Department of Microbiology, The University of Hong Kong, Queen Mary Hospital, Pokfulam Road, Pokfulam, Hong Kong Special Administrative Region, China; kyyuen@hkucc.hku.hk

Received 16 December 2009 Accepted 17 May 2010 Published Online First

5 August 2010

\section{ABSTRACT}

Purpose of study The demographics, clinical features and outcome of patients with pandemic influenza $A$ (H1N1) 2009 infection were compared with a concurrent cohort of patients with seasonal influenza A infection. Study design The clinical and microbiological data of hospitalised adult patients admitted between 29 June and 28 October 2009, with pandemic A (H1N1) 2009 or seasonal influenza A infection, were analysed.

Results $A$ total of 186 patients including 69 pandemic $A$ (H1N1) and 117 seasonal influenza were analysed. The majority $(75 \%)$ under 50 years of age had pandemic $A$ (H1N1). Compared with seasonal influenza, pandemic A (H1N1) patients were younger (median age 47 years vs 76 years, $p<0.001$ ), less likely to have lower respiratory tract symptoms (46.4\% vs $66.7 \%, p=0.007)$, but more likely to be obese $(5.8 \%$ vs $0 \%, p=0.018)$, pregnant (7.2\% vs $0.9 \%, p=0.027)$ or have no underlying predisposing factors $(24.6 \%$ vs $5.1 \%, \mathrm{p}<0.001)$. Patients with pandemic $A(\mathrm{H} 1 \mathrm{~N} 1)$ were more likely to receive oseltamivir (91.3\% vs $40.2 \%, p<0.001)$, but less likely to receive antibiotics (75.4\% vs $90.6 \%, p=0.005)$. Respiratory failure was the reason for intensive care unit admission for all four patients with pandemic A (H1N1), but only for one of three patients with seasonal influenza. There were no statistical significant differences in the rate of intensive care unit admission or death.

Conclusions In addition to age, several clinical parameters were different between pandemic $A$ (H1N1) and seasonal influenza. However, since both seasonal and pandemic influenza can lead to significant morbidity and mortality, the impact of pre-existing seasonal influenza should not be underestimated during the pandemic period.

\section{INTRODUCTION}

Pandemic influenza has been considered to cause greater morbidity and mortality than seasonal influenza, particularly among young adults. ${ }^{1}$ In Mexico, the rate of severe pneumonia during the initial period of pandemic A (H1N1) 2009 was found to be much higher than in preceding years, with deaths predominantly occurring in the younger age group. ${ }^{2}$ Another alarming feature of the current pandemic influenza is that $>30 \%$ of patients with critical illness had no known predisposing conditions. ${ }^{3}$ A few studies involving paediatric patients have undertaken a more detailed comparison between the pandemic A (H1N1) 2009 and seasonal influenza. These studies have identified older children and those with underlying diseases to be found more frequently among hospitalised patients with pandemic A (H1N1) than those with seasonal influenza. ${ }^{4} 5$ The death rate of pandemic $A(\mathrm{H} 1 \mathrm{~N} 1)$ among children and pregnant women is also higher than that of seasonal influenza from previous years. ${ }^{6} 7$ The major limitation of these studies is that historical data were used for comparison. Potential biases may arise when historical controls were used. ${ }^{8}$ For example, the threshold for hospital admission may vary during the pandemic and inter-pandemic period. There have been two studies in the southern hemisphere which concurrently compared pandemic $\mathrm{A}(\mathrm{H} 1 \mathrm{~N} 1)$ and seasonal influenza. The first study, conducted in Sydney, Australia, found that patients with pandemic A (H1N1) were younger and less likely to be immunocompromised than those with seasonal influenza. ${ }^{9}$ In that study, there were no statistically significant differences in the clinical features and outcome between pandemic A (H1N1) and seasonal influenza. In contrast, a study involving eight intensive care units (ICUs) in New South Wales, Australia, showed that the relative risk of admission to ICU of patients with pandemic A (H1NI) was 4.9 times higher than for those with seasonal influenza A infection. ${ }^{10}$

Pandemic A (H1N1) was first introduced into Hong Kong on 30 April 2009. ${ }^{11}$ In this study, we sought to compare concurrently the epidemiology, clinical features, and outcome of hospitalised patients with pandemic and seasonal influenza. We chose to investigate patients hospitalised during the mitigation phase (started from 29 June 2009) to avoid including hospital admissions for isolation purpose only during the preceding containment phase of the pandemic.

\section{METHODS \\ Patients}

This retrospective study was approved by the institutional review board of the Hospital Authority of Hong Kong. Patients with laboratory confirmed influenza A virus infection were identified by the laboratory information system. Inclusion criteria were age 18 years or above; admission to our hospital during the 4 month period between 29 June to 28 October 2009; and positive reverse transcriptase-polymerase chain reaction (RT-PCR) 
for influenza A virus $M$ gene. We excluded patients electively admitted for other medical reasons.

\section{Clinical data collection}

Clinical information was obtained from the clinical management information system. Influenza-like illness was defined as the presence of fever and one of cough, sputum, sore throat or rhinorrhoea. Lower respiratory tract involvement was defined as subjective shortness of breath and physical findings of wheezing or crepitation. Cardiovascular complications were defined as acute coronary syndrome, congestive heart failure or arrhythmia. Acute respiratory distress syndrome (ARDS) and multiorgan failure were defined using standard criteria. ${ }^{12} 13$ Myositis is defined as elevation of creatine kinase $>500 \mathrm{U} / 1$ without elevation of the $\mathrm{MB}$ isoenzyme or troponin.

\section{Laboratory investigations}

The diagnosis and subtyping of influenza A virus was performed by RT-PCR targeting the $M$ gene, seasonal influenza A virus $\mathrm{H} 1$ and $\mathrm{H} 3$ gene, as previously described. ${ }^{11}{ }^{14}$ Real-time one-step RT-PCR assays were used for the detection of pandemic A (H1N1) virus using Invitrogen SuperScript III Platinum OneStep Quantitative Kit in a 7500 Sequence Detection System (Applied Biosystem, Foster City, CA, USA). Briefly, $5 \mu \mathrm{l}$ purified RNA was amplified in a $25 \mu \mathrm{l}$ reaction containing $0.5 \mu \mathrm{l}$ Superscript III Reverse Transcriptase/Platinum Taq DNA polymerase (Invitrogen), $0.05 \mu \mathrm{l}$ ROX reference dye $(25 \mu \mathrm{M}), 12.5 \mu \mathrm{l}$ of $2 \mathrm{X}$ reaction buffer, $800 \mathrm{nmol} / \mathrm{l}$ forward primer $\left(5^{\prime}\right.$ - CCAAAGCTCAGCAAATCCTACAT-3'), corresponding to nucleotides 526 to $548,800 \mathrm{nmol} / 1$ reverse primer (5'-GATGGTGAATGCCCCATAGC-3'), corresponding to nucleotides 576 to 595), and probe $200 \mathrm{nmol} / 1$ (Fam-TGATAAAGGGAAAGAAGTCCT-MGB), corresponding to nucleotides 552 to 572 , designed by multiple alignment of the $\mathrm{HA}$ gene sequences of swine $\mathrm{H} 1$ virus and the pandemic influenza A/California/04/2009 (available in GenBank). Positive control experiments with a pandemic A (H1N1) virus (A/California/04/2009) and negative control experiments with seasonal A (H1N1) and A (H3N2) viruses were performed. Reactions were first incubated at $50^{\circ} \mathrm{C}$ for $30 \mathrm{~min}$, followed by $95^{\circ} \mathrm{C}$ for $2 \mathrm{~min}$, and were then thermal cycled for 50 cycles $\left(95^{\circ} \mathrm{C}\right.$ for $15 \mathrm{~s}, 55^{\circ} \mathrm{C}$ for $30 \mathrm{~s}$ ).

Viral load was determined by quantitative RT-PCR of the influenza A virus $M$ gene. ${ }^{15}$ Direct antigen detection by immunofluorescence using IMAGEN respiratory screen and typing reagents (Oxoid Ely Ltd, Ely, Cambridgeshire, UK) and viral culture using Madin-Darby canine kidney cell monolayer in culture tubes was performed as described elsewhere. ${ }^{16} 17$

\section{Data analysis}

For comparison of pandemic and seasonal influenza, $\chi^{2}$ or Fisher's exact test were used for categorical variables, whereas Mann-Whitney $U$ test or independent sample t test were used for continuous variables where appropriate. Multivariate logistic regression was performed to identify factors independently associated with the type of influenza. SPSS 17.0 for Windows (SPSS Inc, Chicago, Illinois, USA) was used for statistical computation. A value of $\mathrm{p}<0.05$ was considered to represent significant difference.

\section{RESULTS \\ Patient profile}

A total of 186 adult patients were included in this study, with 69 patients infected with the pandemic A (H1N1) 2009 virus, 20 patients with seasonal A (H1) virus, and 97 patients with seasonal A (H3) virus. By comparison, data from the Centre for Health Protection in Hong Kong showed that seasonal influenza virus was isolated from 7366 specimens (6280 H3N2 and 1086 seasonal H1N1 virus), and pandemic A (H1N1) virus was isolated from 22974 specimens, between July and October 2009. ${ }^{18}$ In September 2009, there was a sharp increase in the incidence of influenza A in Hong Kong, mainly related to an increase in pandemic $\mathrm{A}$ (H1N1) virus and to a lesser extent the seasonal influenza virus $\mathrm{H} 3 \mathrm{~N} 2{ }^{19}$

The majority $(39 / 52,75 \%)$ of patients below the age of 50 years were infected with pandemic $\mathrm{A}(\mathrm{H} 1 \mathrm{~N} 1)$, but admissions for seasonal influenza predominated in the age group above 50 (figure 1). The median age of patients with pandemic A (H1N1) was significantly younger than those with seasonal influenza $(p<0.001)$ (table 1). In general, patients with pandemic A (H1N1) were less likely to have underlying predisposing factors than those with seasonal influenza $(p<0.001)$. Specifically, hypertension $(p<0.001)$ or chronic neurological impairment $(p=0.003)$ were less common. However, obese $(p=0.018)$ or pregnant patients $(p=0.027)$ were more common in the pandemic A (H1N1) cohort. There was no statistical difference between reasons for hospital admission (table 2). Among pregnant women with pandemic A (H1N1), one had a spontaneous miscarriage and another had a threatened miscarriage. One pregnant woman with seasonal influenza was hospitalised for decreased fetal movement. Younger age, obesity, and absence of chronic neurological impairment were shown to be independent underlying factors associated with pandemic A (H1N1) by multivariate logistic regression.

\section{Clinical features}

Symptoms of influenza-like illness were more frequent in patients with pandemic A (H1N1), although this did not reach statistical significance $(p=0.156)$ (table 2). Gastrointestinal symptoms (vomiting or diarrhoea) were also more frequent in patients with pandemic A (H1N1), almost reaching statistical significance $(p=0.050)$. Clinical features of lower respiratory tract involvement were less common among patients with pandemic $\mathrm{A}$ (H1N1) $(p=0.007)$, but there was no significant difference in the frequency of pulmonary infiltrate on chest radiograph. There was a wide spectrum of chest radiographic findings in both groups of patients, which can present as lobar consolidation, diffuse alveolar opacities or acute pulmonary oedema (figures 2-4).

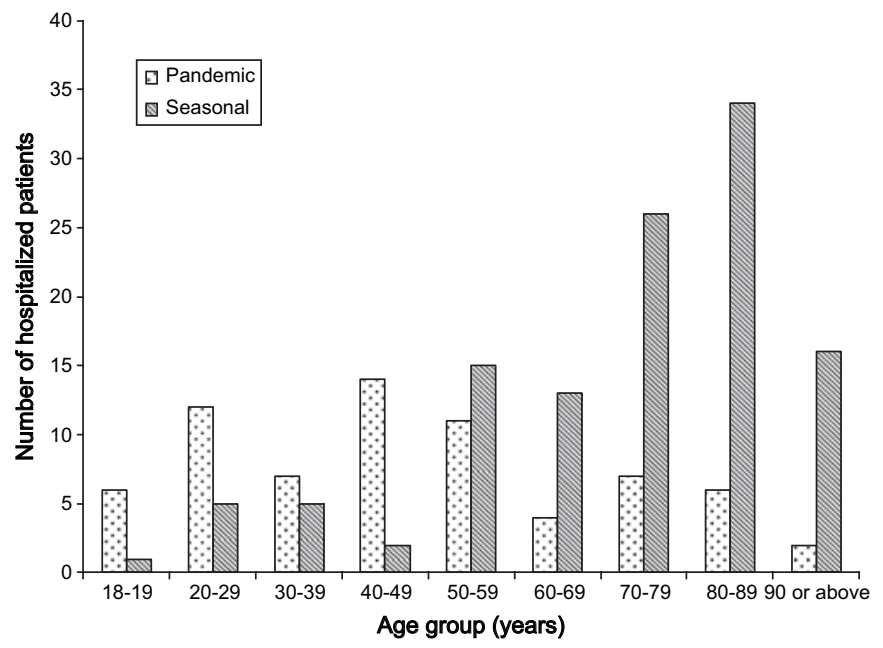

Figure 1 Age distribution of hospitalised patients infected with pandemic influenza A (H1N1) virus and seasonal influenza virus. 
Table 1 Comparison of demographics and underlying predisposing factors between patients with pandemic A (H1N1) and seasonal influenza

\begin{tabular}{|c|c|c|c|}
\hline & $\begin{array}{l}\text { Pandemic A } \\
\text { (H1N1) } \\
(\mathrm{n}=69)\end{array}$ & $\begin{array}{l}\text { Seasonal } \\
\text { influenza } \\
(n=117)\end{array}$ & p Value* \\
\hline \multicolumn{4}{|l|}{ Demographics } \\
\hline Male sex & $29(42.0)$ & $61(52.1)$ & 0.183 \\
\hline Age & $47(29-63)$ & $76(60-86)$ & $<0.001$ \\
\hline \multicolumn{4}{|l|}{ Underlying predisposing factors } \\
\hline Hypertension & $16(23.2)$ & $61(52.1)$ & $<0.001$ \\
\hline Chronic heart disease & $10(14.5)$ & $31(26.5)$ & 0.056 \\
\hline Chronic lung disease & $18(26.1)$ & $34(29.1)$ & 0.663 \\
\hline Chronic liver disease & $4(5.8)$ & $6(5.1)$ & $1.000 \dagger$ \\
\hline Chronic renal disease & $6(8.7)$ & $9(7.7)$ & 0.808 \\
\hline Connective tissue disease & $2(2.9)$ & $2(1.7)$ & $0.628 \dagger$ \\
\hline Chronic neurologic impairment & $4(5.8)$ & $26(22.2)$ & 0.003 \\
\hline Diabetes mellitus & $12(17.4)$ & $27(23.1)$ & 0.357 \\
\hline Malignancy & $11(15.9)$ & $19(16.2)$ & 0.958 \\
\hline HIV infection & $0(0)$ & $1(0.9)$ & $1.000 \dagger$ \\
\hline Transplant & $4(5.8)$ & $3(2.6)$ & $0.427 \dagger$ \\
\hline $\begin{array}{l}\text { Use of immunosuppressive } \\
\text { drugs }\end{array}$ & $6(8.7)$ & $6(5.1)$ & $0.366 \dagger$ \\
\hline Smoker & $9(13.0)$ & $26(22.2)$ & 0.122 \\
\hline Obesity & $4(5.8)$ & $0(0)$ & $0.018 \dagger$ \\
\hline Pregnancy & $5(7.2)$ & $1(0.9)$ & $0.027 \dagger$ \\
\hline No known predisposing factors & $17(24.6)$ & $6(5.1)$ & $<0.001$ \\
\hline
\end{tabular}

Oseltamivir was prescribed more frequently to patients with pandemic A (H1N1), but antibiotics were prescribed more frequently to those with seasonal influenza.

\section{Laboratory investigations}

Elevated alanine transaminase $(\mathrm{p}=0.020)$ and creatinine $(p=0.004)$ concentrations were more common in patients with pandemic A (H1N1) (table 3). Viral culture was performed for all seasonal A (H1) cases and 95 (97.9\%) cases of seasonal A (H3), with all positive viral cultures being $\mathrm{A}(\mathrm{H} 1 \mathrm{~N} 1)$ and $\mathrm{A}(\mathrm{H} 3 \mathrm{~N} 2)$, respectively. Positive viral culture was more frequent in the patients with pandemic A (H1N1) than seasonal influenza $(p=0.025)$ (table 4$)$, and the difference was mainly related to a lower rate of positive viral culture for seasonal A (H3N2). There was no significant difference in the positive rate of direct immunofluorescence or viral load. Two patients with pandemic A (H1N1) (Bacillus species, coagulase negative Staphylococcus) and one patient with seasonal influenza (Micrococcus species) had positive blood culture, but all isolates were considered to be contamination. There was no statistically significant difference in the total number of positive sputum culture and bacterial isolates between the two groups.

\section{Intensive care admissions}

Four patients with pandemic A (H1N1) infection were admitted to the ICU. Three of them were admitted due to respiratory failure from viral pneumonitis, two of whom developed ARDS. The fourth patient, with end stage renal failure, was admitted to the ICU due to acute pulmonary oedema. Of the patients with seasonal influenza, one patient with a history of asthma was admitted to the ICU due to severe infective exacerbation. Another patient, a 26-year-old man with good past health, was
Table 2 Comparison of reason of admission, clinical features, treatment and outcome between patients with pandemic A (H1N1) and seasonal influenza

\begin{tabular}{llll}
\hline & $\begin{array}{l}\text { Pandemic A } \\
\text { (H1N1) } \\
(\mathbf{n = 6 9 )}\end{array}$ & $\begin{array}{l}\text { Seasonal } \\
\text { influenza } \\
(\mathbf{n = 1 1 7 )}\end{array}$ & p Value* $^{*}$ \\
\hline $\begin{array}{l}\text { Days of symptoms before admission } \\
\text { Duration of hospitalisation }\end{array}$ & $2(1-3)$ & $1(1-3)$ & 0.059 \\
& $4(2-7)$ & $3(2-6)$ & 0.224 \\
Reason for admission & & & \\
$\quad \begin{array}{lll}\text { Pulmonary symptoms } \\
\text { Neurological symptoms }\end{array}$ & $47(68.1)$ & $85(72.6)$ & 0.511 \\
$\quad$ Other symptoms & $5(7.2)$ & $13(11.1)$ & 0.389 \\
$\quad$ Exacerbation of underlying disease & $17(24.6)$ & $19(16.2)$ & 0.161 \\
$\quad \begin{array}{l}\text { Pulmonary disease } \\
\quad \text { Other diseases }\end{array}$ & $10(14.5)$ & $24(20.5)$ & 0.305 \\
& $5(7.2)$ & $12(10.3)$ & 0.491
\end{tabular}

Vital signs at accident and emergency department

$\begin{array}{llll}\text { Hypotension } \neq & 16(23.2) & 19(16.2) & 0.241 \\ \text { Pulse }>100 / \text { min } & 32(46.4) & 48(41.0) & 0.476 \\ \text { Respiratory rate }>20 / \text { min } & 14(20.3) & 28(23.9) & 0.566 \\ \text { Temperature } \geq 38^{\circ} \mathrm{C} & 34(49.3) & 62(53.0) & 0.624 \\ \text { Oxygen saturation }<90 \% \text { while } & 12(17.4) & 34(29.1) & 0.075\end{array}$

breathing ambient air

Clinical features

$\begin{array}{llll}\text { Influenza-like illness } & 58(84.1) & 88(75.2) & 0.156\end{array}$

Subjective fever $\quad 62(89.9) \quad 96(82.1) \quad 0.151$

Sore throat or rhinorrhoea $\quad 47(68.1) \quad 63(53.8) \quad 0.056$

$\begin{array}{llll}\text { Cough or sputum } & 59(85.5) & 103(88.0) & 0.619\end{array}$

$\begin{array}{llll}\text { Lower respiratory tract symptoms } & 32(46.4) & 78(66.7) & 0.007\end{array}$

$\begin{array}{llll}\text { Dyspnoea } & 27(39.1) & 55(47.0) & 0.296\end{array}$

Wheezing $\quad 11(15.9) \quad 29(24.8) \quad 0.156$

Crepitation $\quad 25(36.2) \quad 49(41.9) \quad 0.447$

$\begin{array}{llll}\text { Pulmonary infiltrate on chest } \quad 25(36.2) & 52(44.4) & 0.272\end{array}$

radiograph

$\begin{array}{llll}\text { Vomiting or diarrhoea } & 15(21.7) & 13(11.1) & 0.050\end{array}$

Treatment

$\begin{array}{llll}\text { Oseltamivir } & 63(91.3) & 47(40.2) & <0.001 \\ \quad \text { Days of symptoms before } & 3(2-5) & 3(1-4) & 0.252 \\ \begin{array}{l}\text { oseltamivir } \\ \text { Zanamivir }\end{array} & 4(5.8) & 1(0.9) & 0.064 \dagger \\ \text { Antibiotics } & 52(75.4) & 106(90.6) & 0.005\end{array}$

Complications

$\begin{array}{llll}\text { Cardiovascular } & 6(8.7) & 10(8.5) & 0.972 \\ \text { Acute respiratory distress syndrome } & 2(2.9) & 0(0) & 0.136 \dagger \\ \text { Multiorgan failure } & 1(1.4) & 2(1.7) & 1.000 \dagger \\ \text { Myositis } & 0(0) & 2(1.7) & 0.531 \dagger \\ \text { ICU admission } & 4(5.8) & 3(2.6) & 0.427 \dagger \\ \text { Duration of ICU stay (days) } & 2.12(0.84-11.87) & 0.96 & 0.289 \\ & & (0.59-2.81) & \\ \text { Positive pressure ventilation§ } & 4(5.8) & 4(3.4) & 0.472 \dagger \\ \text { Death } & 2(2.9) & 7(6.0) & 0.488 \dagger \\ \text { Days of symptoms before death } & 21(11-31) & 11(6-21) & 0.372\end{array}$

Data are presented as median (interquartile range) for continuous variable, and no. (\%) for categorical variables.

${ }^{*} \chi^{2}$ test was used for categorical variable and Mann-Whitney $U$ test was used for continuous variables unless otherwise stated.

†By Fisher's exact test.

¥Systolic blood pressure $<90 \mathrm{~mm} \mathrm{Hg}$ or diastolic blood pressure $<60 \mathrm{~mm} \mathrm{Hg}$. SInclude mechanical ventilation, bilevel positive airway pressure support, and continuous positive airway pressure support.

ICU, intensive care unit.

admitted to the ICU for close monitoring due to generalised weakness and oxygen desaturation, but spontaneously recovered and stayed in the ICU for only $14 \mathrm{~h}$. The third patient was 


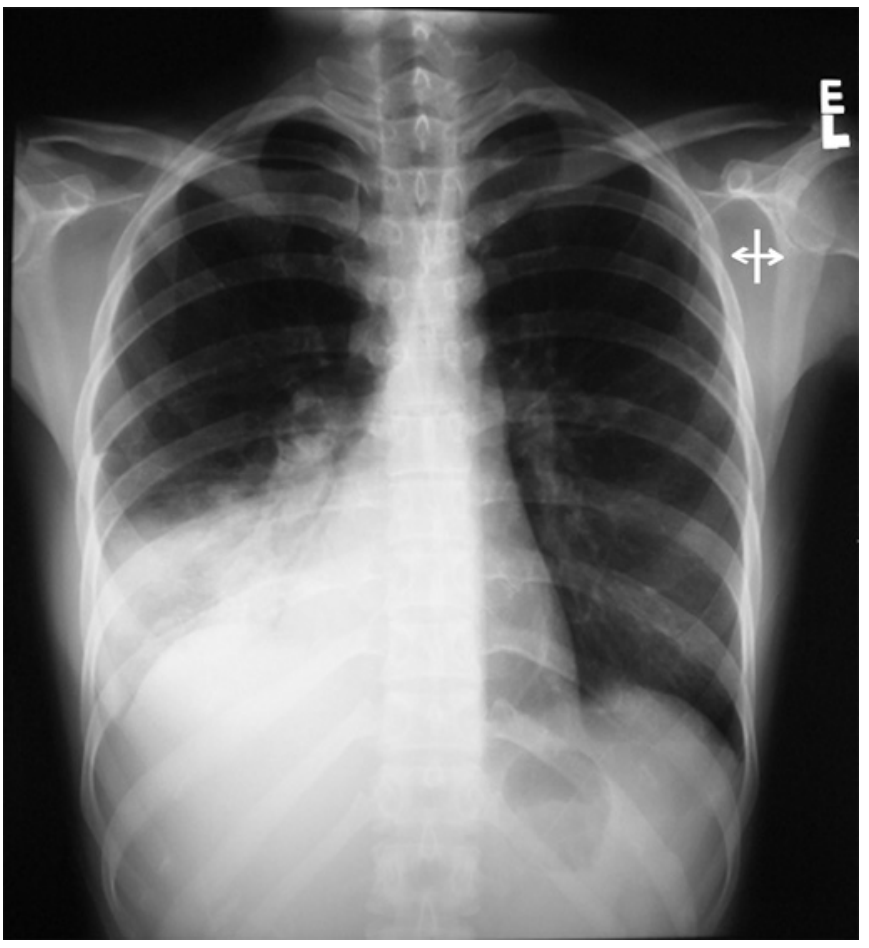

Figure 2 Chest radiograph of a patient with good past health, showing right lower zone consolidation.

admitted with acute perforated duodenal ulcer, and was transferred to the ICU for postoperative care. There was no significant difference in mortality rate between patients with pandemic A (H1N1) and those with seasonal influenza.

\section{DISCUSSION}

This study concurrently compared pandemic A (H1N1) with seasonal influenza for hospitalised adult patients. In contrast to seasonal influenza, those patients with pandemic A (H1N1) were significantly younger and less likely to have underlying predisposing factors, but were more likely to be obese or pregnant. Gastrointestinal symptoms were more frequent in patients with pandemic $\mathrm{A}$ (H1N1), but lower respiratory tract symptoms were less common. Patients with seasonal influenza were less likely to receive antiviral treatment.

As predicted from previous studies using seasonal influenza historical controls ${ }^{2}$ and those of previous pandemics, ${ }^{1}$ our study has confirmed that patients with pandemic A (H1N1) are indeed younger than those with seasonal influenza. The age difference may be explained by the lack of cross-reactive antibody in the younger population. ${ }^{20}$ On the other hand, the absolute number of admissions was higher for patients with seasonal influenza, especially those age 50 years or above. As a comparison, the total number of pandemic A (H1N1) isolated by the Public Health Laboratory Centre of Hong Kong, which receive clinical specimens from both community and hospitalised patients in the entire Hong Kong Special Administrative Region, exceed that of seasonal influenza by more than threefold. ${ }^{18}$ The large number of hospital admissions due to seasonal influenza is related to seasonal A (H3), and may be due to the emergence of A/Perth/ $16 / 2009$, which is antigenically distinct from the current vaccine strain A/Brisbane/10/2007 and A/Uruguay/716/2007. ${ }^{21}$ Therefore, the burden on hospitals due to seasonal influenza during the pandemic period should not be underestimated.

Our results have shown that underlying diseases were more frequent in patients with seasonal influenza, especially hypertension and chronic neurological impairment. Since these factors may be associated with older age, we performed multivariate logistic regression analysis, and found that only chronic neurological impairment remained significantly associated with seasonal influenza. As bidirectional neural-immune communication is an important aspect of the innate immune system, damage to the brain can affect the immune response to infections, as has been demonstrated in patients with stroke. ${ }^{22}$

A case-control study has found obesity to be a risk factor for severe presentations of pandemic A (H1N1), which has not been described for seasonal influenza. ${ }^{23}$ In our study, obese patients were over-represented in hospitalised patients with pandemic A (H1N1) when compared with seasonal influenza, although the absolute number was small. In Hong Kong, the obese population is relatively small, and may explain the lower rate of obesity in our cohort when compared to those in western countries. ${ }^{24}$ In addition to obesity, we have also identified pregnancy as being more common among patients with pandemic A (H1N1) than seasonal influenza, although multivariate logistic regression analysis suggests that this may be related to age. Pregnancy is a widely accepted risk factor for complications in both pandemic and seasonal influenza, ${ }^{25}$ and studies have found that the maternal death rate of pandemic A (H1N1) exceeds that of seasonal influenza in preceding years. ${ }^{7}$ Documented fetal complications of influenza include spontaneous abortion, preterm premature rupture of membrane, and preterm labour. ${ }^{25}$
Figure 3 Chest radiographs of a patient admitted for diabetic ketoacidosis. (A) Chest radiograph was taken on admission, showing early left lower zone infiltration. (B) Rapid progression to bilateral diffuse panlobar involvement (chest radiograph taken $20 \mathrm{~h}$ after the radiograph shown in panel $A$ ).
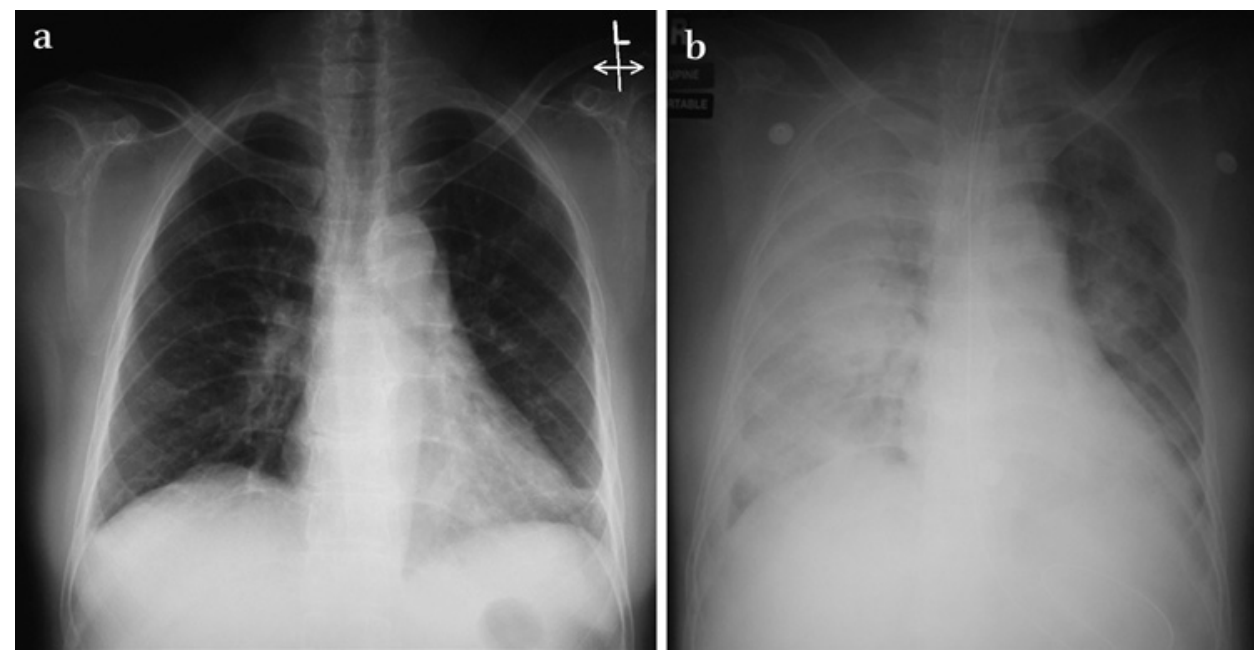
Figure 4 Chest radiographs of a patient with congestive heart failure and end stage renal failure due to diabetic nephropathy. (A) Chest radiograph taken on admission, showing acute pulmonary oedema. (B) Persistent right lower zone infiltrates after diuresis.
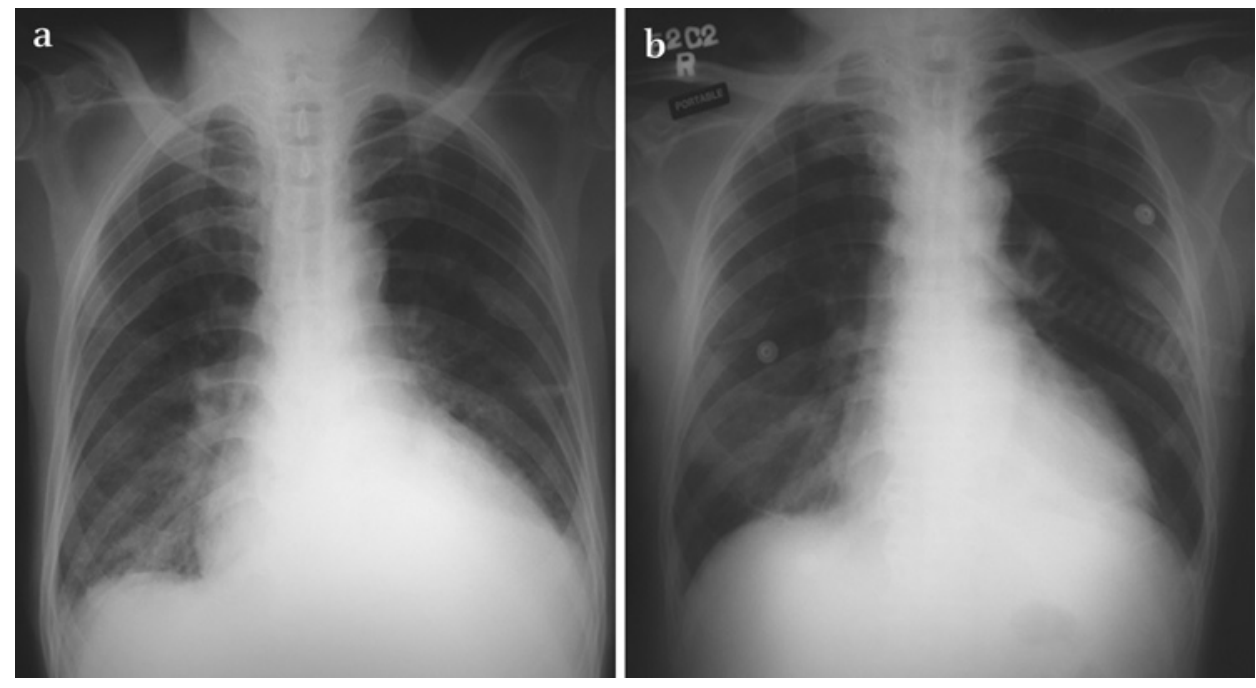

It has been shown that influenza virus can infect the placenta, ${ }^{26}$ and in a recent study influenza virus was shown to replicate in first trimester trophoblast cell lines. ${ }^{27}$

In contrast to the study conducted by Chang et al, ${ }^{9}$ which is also a concurrent analysis of hospitalised patients with pandemic A (H1N1) and seasonal influenza, our study found several differences in the clinical features of patients with pandemic A (H1N1) and seasonal influenza. This may be because our study included more patients, allowing detection of smaller differences. Another factor is that there may be differences in the criteria for hospital admissions. In our cohort, patients with seasonal influenza were more likely to have lower respiratory tract symptoms, but there was no statistical

Table 3 Comparison of selected laboratory tests between patients with pandemic A (H1N1) and seasonal influenza

\begin{tabular}{|c|c|c|c|}
\hline & $\begin{array}{l}\text { Pandemic A } \\
\text { (H1N1) } \\
\text { no./total no. (\%) }\end{array}$ & $\begin{array}{l}\text { Seasonal influenza } \\
\text { no./total no. }(\%)\end{array}$ & p Value* \\
\hline \multicolumn{4}{|l|}{ Blood tests } \\
\hline Leucocytosis $\left(>10.1 \times 10^{9} / I\right)$ & $16 / 67(23.9)$ & $33 / 116(28.4)$ & 0.501 \\
\hline Neutrophilia $\left(>6.7 \times 10^{9} / l\right)$ & $26 / 67(38.8)$ & $45 / 116(38.8)$ & 0.999 \\
\hline Lymphopenia $\left(<1.2 \times 10^{9} / \mathrm{l}\right)$ & $52 / 67(77.6)$ & $94 / 116(81.0)$ & 0.579 \\
\hline $\begin{array}{l}\text { Thrombocytopenia } \\
\left(<170 \times 10^{9} /\right)\end{array}$ & 26/67 (38.8) & $51 / 116(44.0)$ & 0.496 \\
\hline $\begin{array}{l}\text { Elevated alanine transaminase } \\
(>36 \mathrm{IU} / \mathrm{I})\end{array}$ & $17 / 66(25.8)$ & $14 / 115(12.2)$ & 0.020 \\
\hline $\begin{array}{l}\text { Elevated creatinine } \\
(>82 \mu \mathrm{mol} / \mathrm{l})\end{array}$ & $25 / 66(37.9)$ & $69 / 115(60.0)$ & 0.004 \\
\hline $\begin{array}{l}\text { Elevated creatine kinase } \\
\text { (>161 IU/I) }\end{array}$ & 9/37 (24.3) & $18 / 54(33.3)$ & 0.355 \\
\hline Positive sputum culture & $8 / 37(21.6)$ & $14 / 60(23.3)$ & 0.845 \\
\hline Streptococcus pneumoniae & 1 & 2 & $1.000 \dagger$ \\
\hline Staphylococcus aureus & 1 & 0 & $0.371+$ \\
\hline Haemophilus influenzae & 1 & 2 & $1.000 \dagger$ \\
\hline Moraxella catarrhalis & 1 & 0 & $0.371 \dagger$ \\
\hline Klebsiella species & 2 & 1 & $0.556 \dagger$ \\
\hline Pseudomonas aeruginosa & 2 & 4 & $1.000 \dagger$ \\
\hline Others & 0 & $5 \neq$ & $0.159+$ \\
\hline \multicolumn{4}{|c|}{$\begin{array}{l}\text { Data are presented as median (interquartile range) for continuous variable, and no. (\%) for } \\
\text { categorical variables. } \\
{ }^{*} \chi^{2} \text { test was used for categorical variable and Mann-Whitney U test was used for } \\
\text { continuous variables unless otherwise stated. } \\
\dagger \text { By Fisher's exact test. } \\
\ddagger \text { Flavobacterium species (1), Escherichia coli (1), Candida species (2), } \beta \text {-haemolytic } \\
\text { Streptococcus and Candida species (1). }\end{array}$} \\
\hline
\end{tabular}

difference in the frequency of pulmonary infiltrates on chest radiograph. One possibility is that older patients are more susceptible to acute bronchitis after viral infection. On the other hand, diarrhoea or vomiting were also more common among patients with pandemic A (H1N1), almost reaching statistical significance. Although the exact pathogenic mechanism of gastrointestinal symptoms remains uncertain, this is consistent with the results of an in vitro study which demonstrated that more severe cytopathic effect, immunostaining and greater viral replication occurred in intestinal cell lines for pandemic A (H1N1) virus than seasonal influenza $A$ virus. ${ }^{28}$ Despite comparable rates of chronic liver and renal disease, elevated values of both alanine transaminase and creatinine were found more frequently in patients with pandemic A (H1N1), which may represent a predilection for the systemic involvement of pandemic A (H1N1) virus.

In another study using concurrent analysis of pandemic and seasonal influenza, it has been shown that there is a higher risk of ICU admission from pandemic A (H1N1) than seasonal influenza. ${ }^{10}$ However, this has not been observed in our study, and is likely related to major differences in methodology. In their study, the denominator for the rate of ICU admission was the total number of specimens tested positive for influenza A. However, they did not specify whether these specimens were collected from hospitalised patients or outpatients. In our study, on the other hand, the denominator for the rate of ICU admission was the number of hospitalised patients only. Furthermore, we have also analysed the differences in the reasons for admission to ICU. All four patients with pandemic A (H1N1), but only one patient with seasonal influenza, were admitted to the ICU due to severe respiratory distress. Among those infected with pandemic A (H1N1), two had ARDS. This finding is compatible with animal models suggesting more severe involvement of the lower respiratory tract in pandemic A (H1N1) than seasonal influenza virus infection. ${ }^{20}$

Oseltamivir were more frequently prescribed in patients with pandemic $\mathrm{A}(\mathrm{H} 1 \mathrm{~N} 1)$, probably due to the perceived higher risk of complications in this group of patients. However, most studies of oseltamivir were performed in patients with seasonal influenza, and it was shown that treatment with an antiviral reduced the mortality rate in hospitalised patients with seasonal influenza. $^{29}$ On the other hand, antibiotics were more frequently given to patients with seasonal influenza, although the rate of laboratory confirmed bacterial pneumonia was not statistically different. This could be due to the higher frequency of lower 
Table 4 Comparison of the virology profile of pandemic A (H1N1) and seasonal influenza virus infection

\begin{tabular}{|c|c|c|c|}
\hline & $\begin{array}{l}\text { Pandemic A } \\
\text { (H1N1) }\end{array}$ & Seasonal influenza & p Value* \\
\hline \multirow{3}{*}{$\begin{array}{l}\text { Mean viral load } \pm 1 \text { SD } \uparrow\left(\log _{10} M \text { gene }\right. \\
\text { copies/ml) }\end{array}$} & $5.97 \pm 1.62$ & $6.11 \pm 1.32$ & 0.553 \\
\hline & & Seasonal A (H1N1): $6.53 \pm 1.33$ & $0.189 \dagger$ \\
\hline & & Seasonal A (H3N2): $6.02 \pm 1.31$ & $0.810 \ddagger$ \\
\hline \multirow{3}{*}{$\begin{array}{l}\text { Positive direct antigen detection by } \\
\text { immunofluorescence, no./total no. (\%) }\end{array}$} & $43 / 65(66.2)$ & $86 / 115(74.8)$ & 0.217 \\
\hline & & Seasonal A (H1): 16/19 (84.2) & $0.130 \dagger$ \\
\hline & & Seasonal A (H3): 70/96 (72.9) & $0.357 \ddagger$ \\
\hline \multirow[t]{3}{*}{ Positive viral culture, no./total no. (\%) } & $55 / 65(84.6)$ & $80 / 115(69.6)$ & 0.025 \\
\hline & & Seasonal A (H1N1): 16/20 (80) & $0.731 \dagger \S$ \\
\hline & & Seasonal A (H3N2): $64 / 95$ (67.3) & $0.014 \ddagger$ \\
\hline
\end{tabular}

\footnotetext{
$* \chi^{2}$ test was used for categorical variable and independent sample $t$ test was used for continuous variables unless otherwise stated. †Comparison between pandemic $A(\mathrm{H} 1 \mathrm{~N} 1)$ and seasonal $\mathrm{A}$ (H1N1).

$\ddagger$ Comparison between pandemic $A(H 1 N 1)$ and seasonal $A(H 3 N 2)$.

$\S B y$ Fisher's exact test.

qViral load was available for 55 patients with pandemic A (H1N1), 111 patients with seasonal influenza (18 patients with seasonal A (H1N1) and 93 patients with seasonal A (H3N2)).
}

respiratory tract symptoms in patients with seasonal influenza. Previous studies showed that patients with acute bronchitis were more likely to be treated with antibiotics than patients with upper respiratory tract infections. ${ }^{30}$

\section{Limitations}

There are several limitations in our study. First, we have only included adult patients, and therefore our findings cannot be generalised to the whole population. If we included children, the difference in age may even be greater because previous studies have shown that children hospitalised for pandemic A (H1N1) are older than those for seasonal influenza. ${ }^{4}$ Secondly, only hospitalised patients were analysed in this study. The threshold for admission may be influenced by age or underlying diseases. Thirdly, as in all retrospective studies, all clinical information was based on reviewing of clinical records. Some symptoms may be missed because the attending physician did not elicit such a history. However, because the diagnosis was not known at admission for most patients, these problems affected all patients

\section{Main messages}

- Patients with pandemic A (H1N1) virus infection are younger, more likely to be obese, or pregnant, and less likely to have underlying predisposing factors than those with seasonal influenza.

- Seasonal influenza can lead to significant morbidity and mortality during the pandemic period, and the impact should not be underestimated.

\section{Current research questions}

- What is the difference in demographics, clinical features and outcomes between pandemic A (H1N1) and seasonal influenza in the community setting?

- Why are obese patients more likely to develop complications due to influenza? with pandemic and seasonal influenza. Another potential limitation in our study is that body height and body weight were not recorded for most patients, and therefore some patients with obesity may have been missed. Because antiviral treatment was more frequently given to patients with pandemic H1N1, this should theoretically improve the outcome of such patients, and may affect the interpretation on the differences in outcome between pandemic and seasonal influenza. Finally, the relatively small sample size prohibited the detection of small differences between the two groups.

\section{Conclusion}

By evaluating patients with pandemic and seasonal influenza hospitalised during the same period, this study allowed us to provide an unbiased view on the differences between infections caused by these two types of influenza virus subtypes. Though pandemic influenza causes great concern, especially among healthy young adults, the impact of seasonal influenza should not be overlooked.

Acknowledgements We would like to thank Alan KL Wu, Sandy KY Chau, and Amy CY Wong for critical review of the manuscript.

Funding Providence Foundation Limited in memory of the late Dr Lui Hac Minh, the University Grant Council, and the Research Fund for the Control of Infectious Diseases (RFCID) of the Food and Health Bureau of the Hong Kong SAR Government.

\section{Competing interests None declared.}

Ethics approval This study was conducted with the approval of the institutional review board of the Hospital Authority of Hong Kong.

Provenance and peer review Not commissioned; externally peer reviewed.

\section{REFERENCES}

1. Simonsen L, Clarke MJ, Schonberger LB, et al. Pandemic versus epidemic influenza mortality: a pattern of changing age distribution. J Infect Dis 1998;178:53-60.

2. Chowell G, Bertozzi SM, Colchero MA, et al. Severe respiratory disease concurrent with the circulation of H1N1 influenza. N Engl J Med 2009;361:674-9.

3. Webb SA, Pettila V, Seppelt I, et al. Critical care services and 2009 H1N1 influenza in Australia and New Zealand. N Engl J Med 2009;361:1925-34.

4. O'Riordan S, Barton M, Yau Y, et al. Risk factors and outcomes among children admitted to hospital with pandemic H1N1 influenza. CMAJ 2010;182:39-44.

5. Centers for Disease Control and Prevention (CDC). Surveillance for pediatric deaths associated with 2009 pandemic influenza A (H1N1) virus infection-United States, April-August 2009. MMWR Morb Mortal Wkly Rep 2009;58:941-7.

6. Libster R, Bugna J, Coviello S, et al. Pediatric hospitalizations associated with 2009 pandemic influenza A (H1N1) in Argentina. N Engl J Med 2010;362:45-55.

7. ANZIC Influenza Investigators and Australasian Maternity Outcomes Surveillance System. Critical illness due to 2009 A/H1N1 influenza in pregnant and 
postpartum women: population based cohort study. BMJ 2010:340:c1279. doi:10.1136/bmj.c1279.

8. Miller AB, Goff DC, Bammann K, et al. Cohort studies. In: Ahrens W, Pigeot I, eds. Handbook of epidemiology. Berlin: Springer, 2005:253-85.

9. Chang YS, van Hal SJ, Spencer PM, et al. Comparison of adult patients hospitalised with pandemic (H1N1) 2009 influenza and seasonal influenza during the "PROTECT" phase of the pandemic response. Med J Aust 2010;192:90-3.

10. Dalton CB, Cretikos MA, Durrheim DN, et al. Comparison of adult patients hospitalised with pandemic (H1N1) 2009 influenza and seasonal influenza during the "PROTECT" phase of the pandemic response. Med J Aust 2010;192:356-8.

11. Lau SK, Chan KH, Yip CC, et al. Confirmation of the first Hong Kong case of human infection by novel swine origin influenza A (H1N1) virus diagnosed using ultrarapid, real-time reverse transcriptase PCR. J Clin Microbiol 2009;47:2344-6.

12. Bernard GR, Artigas A, Brigham KL, et al. The American-European Consensus Conference on ARDS. Definitions, mechanisms, relevant outcomes, and clinical trial coordination. Am J Respir Crit Care Med 1994;149:818-24.

13. Estenssoro E, Reina R, Canales HS, et al. The distinct clinical profile of chronically critically ill patients: a cohort study. Crit Care 2006;10:R89.

14. Li IW, Hung IF, To KK, et al. The natural viral load profile of patients with pandemic swine-origin influenza A H1N1 2009 (pH1N1) and the effect of oseltamivir treatment. Chest. Published Online First: 2010 Jan 8 doi:10.1378/chest.09-3072.

15. To KK, Chan KH, Li IW, et al. Viral load in patients infected with pandemic H1N1 2009 influenza A virus. J Med Virol 2010;82:1-7.

16. Chan $\mathbf{K H}$, Maldeis N, Pope W, et al. Evaluation of the Directigen FluA+B test for rapid diagnosis of influenza virus type $A$ and $B$ infections. J Clin Microbiol 2002:40:1675-80.

17. Yuen KY, Chan PK, Peiris M, et al. Clinical features and rapid viral diagnosis of human disease associated with avian influenza A H5N1 virus. Lancet 1998;351:467-71.

18. Centre for Health Protection. Monthly summary tables of influenza virus isolation. 2009. http://www.chp.gov.hk/en/data/5/26/44/292/377.html (accessed 22 Mar 2010).
19. Centre for Health Protection. Swine and seasonal flu monitor. 2009. http://www. chp.gov.hk/files/pdf/ssfm_4_11_09.pdf (accessed 22 Mar 2010).

20. Itoh $\mathbf{Y}$, Shinya $\mathrm{K}, \mathrm{Kiso} \overline{\mathrm{M}}, \overline{e t} \mathrm{al}$. In vitro and in vivo characterization of new swineorigin H1N1 influenza viruses. Nature 2009;460:1021-5.

21. World Health Organization. Recommended composition of influenza virus vaccines for use in the 2010 influenza season (southern hemisphere winter). Wkly Epidemiol $\operatorname{Rec}$ 2009;84:421-31.

22. Meisel C, Schwab JM, Prass K, et al. Central nervous system injury-induced immune deficiency syndrome. Nat Rev Neurosci 2005:6:775-86.

23. Morgan OW, Bramley A, Fowlkes A, et al. Morbid obesity as a risk factor for hospitalization and death due to 2009 pandemic influenza A (H1N1) disease. PLoS One 2010;5:e9694.

24. Ko GT, Tang JS. Prevalence of obesity, overweight and underweight in a Hong Kong community: the United Christian Nethersole Community Health Service (UCNCHS) primary health care program 1996-1997. Asia Pac J Clin Nutr 2006;15:236-41.

25. Rasmussen SA, Jamieson DJ, Bresee JS. Pandemic influenza and pregnant women. Emerg Infect Dis 2008;14:95-100.

26. Rosztoczy I, Sweet C, Toms GL, et al. Replication of influenza virus in organ cultures of human and simian urogenital tissues and human foetal tissues. $\mathrm{Br} J$ Exp Pathol 1975;56:322-8.

27. Trinh QD, Izumi $Y$, Komine-Aizawa $S$, et al. H3N2 influenza A virus replicates in immortalized human first trimester trophoblast cell lines and induces their rapid apoptosis. Am J Reprod Immunol 2009;62:139-46.

28. Li IW, Chan KH, To KW, et al. Differential susceptibility of different cell lines to swine-origin influenza A H1N1, seasonal human influenza A H1N1, and avian influenza A H5N1 viruses. J Clin Virol 2009:46:325-30.

29. McGeer A, Green KA, Plevneshi A, et al. Antiviral therapy and outcomes of influenza requiring hospitalization in Ontario, Canada. Clin Infect Dis 2007;45:1568-75.

30. Gonzales R, Steiner JF, Sande MA. Antibiotic prescribing for adults with colds, upper respiratory tract infections, and bronchitis by ambulatory care physicians. JAMA 1997;278:901-4. 


\section{PMJ}

\section{Concurrent comparison of epidemiology, clinical presentation and outcome between adult patients suffering from the pandemic influenza A (H1N1) 2009 virus and the seasonal influenza A virus infection}

Kelvin K W To, Samson S Y Wong, Iris W S Li, et al.

Postgrad Med J 2010 86: 515-521 originally published online August 5, 2010

doi: 10.1136/pgmj.2009.096206

Updated information and services can be found at:

http://pmj.bmj.com/content/86/1019/515.full.html

\section{These include:}

References This article cites 26 articles, 8 of which can be accessed free at: http://pmj.bmj.com/content/86/1019/515.full.html\#ref-list-1

Article cited in:

http://pmj.bmj.com/content/86/1019/515.full.html\#related-urls

Email alerting Receive free email alerts when new articles cite this article. Sign up in service the box at the top right corner of the online article.

Topic Articles on similar topics can be found in the following collections Collections

Drugs: infectious diseases (2502 articles)

Obesity (nutrition) (3161 articles)

Pregnancy (15903 articles)

Reproductive medicine (27710 articles)

Adult intensive care (1849 articles)

Epidemiology (5431 articles)

\section{Notes}

To request permissions go to:

http://group.bmj.com/group/rights-licensing/permissions

To order reprints go to:

http://journals.bmj.com/cgi/reprintform

To subscribe to BMJ go to:

http://group.bmj.com/subscribe/ 